\title{
Gênero na perspectiva decolonial: revisão integrativa no cenário latino-americano
}

\author{
Magda Dimenstein 1 (i) 0000-0002-5000-2915 \\ Gabriel de Nascimento e Silva' (iD) 0000-0001-5647-2750 \\ Candida Dantas $^{1}$ (iD) 0000-0003-4778-9400 \\ João Paulo Macedo² (i) 0000-0003- 4393-8501 \\ Jáder Ferreira Leite ${ }^{1}$ (iD) 0000-0002-6045-531X \\ Antonio Alves Filho' (iD 0000-0001-8370-1096
}

'Universidade Federal do Rio Grande do Norte, Natal, RN, Brasil.

59078-970-ufrn@ufrn.br

2Universidade Federal do Piauí, Parnaíba, PI, Brasil.64049-550 - scs@ufpi.edu.br

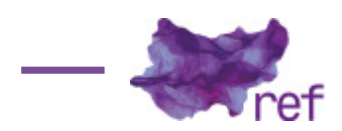

Resumo: Interessa-nos investigar as principais contribuições latino-americanas dos estudos decoloniais sobre o conceito de gênero, pois entendemos que tal conceito pode operar uma forma de colonialidade ao invisibilizar a multiplicidade de cosmovisões e práticas socioculturais que produzem relações sociais diferenciadas. Para tanto, realizamos uma revisão integrativa da produção científica sobre gênero em articulação com o pensamento decolonial no Portal de Periódicos CAPES e na Redalyc. Após o crivo de inclusão-exclusão, 35 artigos foram analisados. Os resultados apontam para: (a) negação do sujeito universal do feminismo; (b) compreensão de gênero, raça e classe como variáveis coconstitutivas; e (c) questionamento sobre a aplicação do conceito em realidades com diferentes lógicas culturais. $A$ discussão sobre gênero na perspectiva decolonial vem se fortalecendo, especialmente no Brasil, mas ainda demanda esforços em pensar as heranças da colonialidade na atualidade.

Palavras-chave: gênero; decolonialidade; América Latina.

Gender in the Decolonial Perspective: An Integrative View of the Latin American Scenario Abstract: We are interested in investigating the main Latin American contributions to decolonial studies about the concept of gender, as we understand that it can operate as a type of coloniality as it makes invisible many worldviews and socio-cultural practices that produce different social relations. For this end, we made an integrative view of scientific production on gender alongside decolonial thought on the Portal de Periódicos CAPES and on Redalyc. After applying the inclusion-exclusion criteria, 35 articles were analyzed. The results pointed to (a) denial of the feminist universal subject; (b) the understanding of gender, race and class as co-constitutive variables; and (c) questioning the applicability of the concept in different cultural logics. The discussion on gender on the decolonial perspective has been strengthened, especially in Brazil, but it still demands efforts on reflections on colonial inheritances in current times. Keywords: Gender; Decolonialism; Latin America.

Género en la perspectiva decolonial: revisión integrativa en el escenario latinoamericano Resumen: Nos interesa investigar las principales contribuiciones latinoamericanas de los estudios decoloniales acerca del concepto de género, porque entendemos que el mismo puede operar una forma de colonialidad al invisibilizar la multiplicidad de cosmovisiones y prácticas socioculturales que producen relaciones sociales diferenciadas. Para tanto, realizamos una revisión intregrativa de la producción científica sobre género en articulación con el pensamiento decolonial en los Periódicos CAPES y en Redalyc. Después del proceso de inclusión-exclusión, 35 artículos fueron analizados. Los resultados apuntan para: (a) negación del sujeto universal del feminismo; (b) comprensión de género, raza y clases como variables co-constitutivas; y (c) cuestionamiento sobre la aplicación del concepto en realidades con diferentes lógicas culturales. La discusión sobre género en la perspectiva decolonial 
viene fortaleciéndose, especialmente en Brasil; sin embargo aún demanda esfuerzos por pensar las herencias de la colonialidad en la actualidad.

Palabras claves: género; decolonialidad; América Latina.

\section{Introdução}

Nuestro camino es otro, porque hemos sido y somos la "otra-cara" de la modernidade (Enrique Dussel)

O pensamento decolonial tem evocado a busca por saberes que levam em consideração a colonização como fator histórico determinante da organização social mundial e a colonialidade como reflexo de uma imposição política e epistemológica. Tal perspectiva teórico-política abala as consolidadas estruturas do pensamento europeu hegemônico e dá visibilidade às racionalidades periféricas, incluindo o território que se convencionou chamar de América Latina'. Neste sentido, busca romper com a homogeneização dos saberes e produzir uma ontologia política que defende a vida em toda sua multiplicidade de formas e sentidos, ancorada no relacional e comunitário, na diversidade e mutabilidade, incorporando diferentes cosmovisões, práticas culturais, raças/etnias, gêneros etc.

Neste artigo pretendemos destacar, a partir de uma revisão integrativa de literatura, contribuições de estudos decoloniais latino-americanos acerca do conceito de gênero, o qual constitui um dos principais operadores do pensamento científico e ordenador das práticas socioculturais na contemporaneidade. A análise proposta está articulada a um projeto de pesquisa que tem seu foco nos processos de autonomia, gestão do cotidiano e modos de vida de mulheres moradoras de comunidades quilombolas rurais e beneficiárias de uma política social nos estados do Rio Grande do Norte (RN) e Piauí (PI). ${ }^{2}$ Interessa-nos investigar o cotidiano de mulheres nos contextos rurais brasileiros, dado que, historicamente, esse grupo tem sido invisibilizado nos espaços acadêmicos, em especial, no campo da Psicologia. O meio rural, diferentemente do que se costuma pensar, não é homogêneo, constituindo-se de espaços bastante diversos. Observa-se uma multiplicidade de condições e modos de vida, bem como de relações sociais, dentre elas, as relações de gênero. Esse cenário convoca, portanto, a uma outra leitura sobre gênero (Rita MACIAZEKIGOMES; Conceição NOGUEIRA; Maria Juracy TONELI, 2016). Dessa forma, consideramos que o pensamento decolonial, ao problematizar a manutenção das condições de produção de conhecimento, pode trazer uma série de novos aportes analíticos às investigações que articulam gênero, raça/etnia e contextos rurais.

\section{O movimento decolonialista e a emergência de um feminismo decolonial}

Os estudos pós-coloniais e decoloniais surgem no meio acadêmico como um movimento epistemológico e político contra as situações de dominação e opressões diversas que se instauram na relação antagônica e hierárquica entre colonizador e colonizado. Estas perspectivas tomam os processos de colonização e suas repercussões como ponto-chave em suas teorizações, pois, como fato histórico, permitiu a ampliação de suas fronteiras materiais, políticas, econômicas, epistemológicas e simbólicas do continente europeu, à custa da dominação, repressão, invisibilização e violência contra outros povos e culturas.

Por meio dos processos de colonização são forjados distintos sujeitos: de um lado, têm-se os colonizados como aqueles ditos atrasados, selvagens, irracionais e inferiores, categoria que se estabelece a partir de um paradigma essencialista; e, de outro, os colonizadores vistos como seres desenvolvidos, racionais, superiores, modelo de sujeito tomado como universal. O psiquiatra Franz Fanon (1925-1961) (2008) problematizava essa questão em meados do século XX na sua célebre obra Pele negra, máscaras brancas, onde analisa a alienação colonial, estruturante da sociedade moderna, e caracterizada por uma perda de si ou da capacidade de se autodeterminar de certos indivíduos ou grupos sociais, e sua subordinação às condições concretas de exploração colonialcapitalista e incorporação dos valores dominantes do colonizador (FANON, 2008; Deivison Mendes FAUSTINO, 2013).

\footnotetext{
${ }^{1}$ Ressaltamos que a noção de América Latina é uma invenção da colonial-modernidade, pois foi por meio da invasão europeia que ocorreu a supressão de diversos povos, racionalidades e culturas que ocupavam este local, bem como a constituição do território mundialmente conhecido como América Latina.

${ }^{2}$ Trata-se da pesquisa "O Programa Bolsa Família no contexto dos assentamentos de reforma agrária: autonomia, gestão do cotidiano e modos de vida de mulheres", financiada pela Chamada Publica Universal 01/2016 do Conselho Nacional do Desenvolvimento Científico e Tecnológico/CNPq.
} 
A relação entre esses distintos sujeitos é marcada pela subalternização da diferença, seja ela do saber, do poder e/ou do ser. Neste sentido, as teorias pós-coloniais vêm demonstrar as relações de poder e as formas de conhecimento que conduziram os sujeitos imperiais europeus e norte-americanos a efetivarem um projeto colonizador de domínio e opressão (Adriana PISCITELLI, 2013). Todavia, o termo pós-colonial, adotado por essas teorias, remete a dois entendimentos distintos. O primeiro deles diz respeito aos processos históricos, em meados do século XX, de descolonização e independência dos povos submetidos ao regime imperialista e à colonização, supondo uma superação do colonialismo. A segunda utilização do termo se refere ao movimento epistêmico e político de crítica à modernidade eurocentrada promovida pelo grupo sul-asiático de Estudos Subalternos, que começa a ganhar notoriedade internacional por volta dos anos 1980, tendo como principais expoentes Ranjit Guha, Gayatry Spivak, Partha Chatterjee e Dipesh Chakrabarty (Luciana BALLESTRIN, 2013).

A crítica desses estudos foi direcionada à visão tradicional e única da história, que apresenta o mundo europeu como centro moderno da racionalidade e firmou-se como paradigma dominante supostamente capaz de abarcar todas as esferas da vida humana nos mais variados locais do globo (Cândida Beatriz ALVES; Polianne DELMONDEZ, 2015). Conforme aponta Divanize Carbonieri (2016, p. 281), o conhecimento científico nos países ocidentalizados é produzido predominantemente por homens europeus oriundos da Itália, França, Alemanha, Reino Unido e Estados Unidos da América. Esse cenário tem provocado muitos questionamentos sobre a centralidade na produção do conhecimento, pois "o mundo é bem maior do que esses cinco países e certamente do que os homens desses cinco países". Essa crítica destaca os sujeitos subalternos como aqueles cuja voz não é ouvida, que sempre é expressa por intermédio de um outro que fala em seu nome. Tais sujeitos constituem um grupo que historicamente tem sido silenciado pelos grupos dominantes. Apesar disso, reivindicam seu lugar enquanto sujeitos do conhecimento dotados de historicidade (BALLESTRIN, 2013).

A partir da crescente popularidade das teorizações do grupo sul-asiático e do pensamento pós-colonial, essas discussões chegam aos territórios latino-americanos. Começam a despontar várias críticas aos legados das colonizações. Mesmo assim, teóricos latino-americanos como o semiólogo argentino Walter Mignolo e o sociólogo porto-riquenho Ramón Grosfoguel questionam radicalmente a influência massiva de autores europeus nas críticas pós-coloniais e subalternas. Eles entendem que a lógica eurocêntrica de produção do conhecimento e o apagamento da trajetória singular da América Latina em termos de dominação e resistência ao colonialismo se mantêm ocultos no debate (BALLESTRIN, 2013). Este impasse teórico marca o distanciamento das teorias pós-coloniais e o aparecimento do paradigma decolonial. ${ }^{3}$ Para tais autores, a opção pelo termo "decolonial" refere-se ainda ao entendimento de que não estamos em uma época pós-colonial, uma vez ainda estarmos presos a pressupostos econômicos, culturais e epistêmicos da colonialidade. Por mais que as nações da América Latina tenham superado as situações de colonização, ainda repercutem reflexos da colonialidade do poder (Aníbal QUIJANO, 2005; BALLESTRIN, 2013).

Neste sentido, ainda que as duas perspectivas foquem no resgate epistêmico do oprimido e na visão do subalterno, diferem quanto ao modo de abordar a questão da subalternidade. Sobre isso, comenta Carbonieri (2016, p. 295):

O Grupo Sul-Asiático de Estudos Subalternos lia a subalternidade a partir de uma crítica pósmoderna, ou seja, uma crítica eurocêntrica do eurocentrismo. Já o Grupo Latino-Americano leria a subalternidade a partir de uma crítica decolonial, ou seja, uma crítica do eurocentrismo a partir de conhecimentos que foram subalternizados e silenciados pelo eurocentrismo.

Além disto, a crítica pós-colonial restringe-se às colonizações francesa e britânica dos países asiáticos, africanos e oceânicos, que se expandiram entre os séculos XIX e XX. Não considera a colonização ibérica nas Américas três séculos antes, deixando em aberto uma lacuna histórica sobre o continente. A partir disso, teóricos da América Latina passam a defender que foi a conquista das Américas e, consequentemente, o extermínio de seus povos tradicionais e culturas, o marco fundante de um projeto civilizatório que se convencionou chamar de modernidade, marcada pela imposição da racionalidade europeia a todo o globo (CARBONIERI, 2016). O pensamento decolonial ressalta o papel central do território latino-americano para o desenvolvimento do capitalismo mundial, já que foi o primeiro espaço físico e simbólico a sofrer as consequências do sistema colonial/imperial moderno (Eliene Amorim ALMEIDA; Janssen Felipe da SILVA, 2015) que forjou lugares e papéis sociais subjugados para uma determinada parcela da sociedade.

\footnotetext{
${ }^{3}$ A opção pelo termo "decolonial" refere-se ainda ao entendimento de que não estamos em uma época pós-colonial, uma vez que ainda estamos presos a pressupostos econômicos, culturais e epistêmicos da colonialidade. Por mais que as nações da América Latina tenham superado as situações de colonização, ainda repercutem reflexos da colonialidade do poder.
} 
Frente a isso, o sociólogo peruano Aníbal Quijano (2005) desenvolve a noção de colonialidade enquanto um sistema hierárquico de classificação dos saberes, locais e pessoas que vai além dos processos históricos de colonização, pois perpetua uma lógica de "opressão e inferiorização do outro que não seja o homem heterossexual/branco/patriarcal/militar/capitalista/ europeu" e repercute, ałualmente, na organização da sociedade, bem como em suas instituições, estruturas e subjetividades (Paulo Henrique MARTINS; Júlia Figueredo BENZAQUEN, 2017, p. 18).

As ideias do autor são amplamente utilizadas nos estudos decolonialistas, pois orientam para um novo entendimento das relações sociais. O padrão de poder mundial que se desenvolve no capitalismo colonial/moderno, a partir da conquista e constituição da América, em 1492, cria identidades sociais até então inexistentes, como a de índio, de negro e de mestiço, por meio da ideia de raça. Tomando como base diferenças biológicas, a raça justifica o lugar ocupado por conquistadores e conquistados e tem sido utilizada desde então para legitimar e perpetuar relações de dominação impostas nos processos de colonização. Assim, negros, índios e mestiços passam a ser destinados à servidão e escravidão, ao passo que, para os brancos e europeus, são reservados os lugares e trabalhos de prestígio (QUIJANO, 2005).

Esse processo de classificação, hierarquização e controle da população global sustentado na ideia de raça é descrito por Quijano (2005) como colonialidade do poder. Conforme o autor, a colonialidade não se encerra no colonialismo, mas é atualizada e legitimada pelas relações de poder que naturalizam as assimetrias que incidem sobre pessoas, subjetividades, saberes, ou seja, sobre todas as esferas da existência social cotidiana. Aliado a isso, tem-se ainda a falácia da modernidade como um eixo de sustentação do capitalismo eurocentrado e global que, assentado nas experiências do colonialismo e colonialidade, cria um universo de relações intersubjetivas propícias à dominação (María LUGONES, 2008). Neste sentido, é possível observar que os efeitos da colonialidade se materializam nas mais diversas práticas cotidianas, nas relações patriarcais, racistas e sexistas, na relação urbano-rural, dentre outras.

Associada à colonialidade do poder, tem-se a colonialidade do saber. Trata-se de um padrão de poder mundial que recai sobre os valores culturais e intelectuais de modo a permitir a desvalorização de saberes e práticas e garantir a superioridade de outros (MARTINS; BENZAQUEN, 2017), reproduzindo o status quo das relações entre centro e periferia e as hierarquias étnicoraciais. Nesse modelo, as cosmologias e os conhecimentos subalternos são representados como uma etapa mítica, pré-moderna e pré-científica no desenvolvimento linear das sociedades, ao passo que é no Norte global ${ }^{4}$ onde teorias universalistas são pensadas e exportadas, gerando um processo de dependência acadêmica (BALLESTRIN, 2017).

Nesse sentido, torna-se imperioso questionar o lugar epistêmico do enunciador, bem como "evidenciar a ego-geo-política e a corpo-política do conhecimento, descortinando o território, a cor, raça, etnia, identidade sexual e de gênero, do sujeito cognoscente" (ALMEIDA; SILVA, 2015, p. 51-52). Em outras palavras, faz-se necessário resgatar a historicidade de pessoas e locais e suas múltiplas determinações.

Com isso, o pensamento decolonial convoca o Sul global a formular conhecimentos situados, adequados ao seu contexto e aos seus povos, que não sejam simplesmente importados e adaptados do centro. Urgem esforços de aprender sobre o Sul com o Sul, indo além das teorias produzidas no Norte Global, conforme a proposta das Epistemologias do Sul de Boaventura de Sousa Santos (2009). Impera a busca pelo resgate das histórias, memórias, dores, línguas e saberes que dizem respeito ao lugar de enunciação dos sujeitos envolvidos (MARTINS; BENZAQUEN, 2017), sendo essa a proposta dos pensadores do grupo latino-americano Modernidade/Colonialidade. Contudo, nos lembram Martins e Benzaquen (2017) que, frente aos conhecimentos hegemônicos da Europa e demais países centrais do capitalismo, não devemos e nem podemos desconsiderar tudo que foi e é produzido nesses países, mas promover uma libertação de saberes e práticas outrora desvalorizados e invisibilizados.

É nesse campo de tensões entre perspectivas pós-coloniais e decoloniais que se dá o encontro com os feminismos como uma tentativa de geopolitização do debate feminista, interpelando os feminismos ocidentais e universalizantes, em que o gênero pode operar uma forma de colonialidade ao essencializar e invisibilizar a multiplicidade de práticas culturais e cosmovisões que produzem relações sociais diferenciadas, sobretudo, no contexto específico da América Latina. Trazem contribuições relevantes para nossa pesquisa na medida em que permitem descortinar a opressão e a dominação de gênero e raça em relação às mulheres e à população negra. Por se tratar de um caminho teórico muito importante na atualidade, tal perspectiva será mais amplamente discutida adiante.

\footnotetext{
${ }^{4}$ Norte e Sul global são entendidos aqui não como territórios geográficos, mas como metáfora do sofrimento humano causado pelo capitalismo. São reflexo dos modos de exploração entre centro e periferia do sistema mundial. Todavia, não devem ser reduzidos a um binarismo conceitual, pois essas fronteiras são fluidas, porosas, e permitem a existência de representações do Sul no Norte bem como do Norte no Sul.
} 


\section{Procedimentos metodológicos}

A estratégia metodológica adotada no presente trabalho foi a revisão integrativa de literatura que tem a finalidade de mapear o estado da arte de uma temática, a partir da sistematização dos principais resultados e da identificação de possíveis lacunas com vistas a favorecer um aprofundamento sobre a problemática investigada, bem como apontar novas (Marcela Tavares de SOUZA; Michelly Dias da SILVA; Rachel de CARVALHO, 2010).

Para tanto, foram levantados artigos científicos nas seguintes bases de dados: Portal de Periódicos CAPES e Rede de Revistas Científicas da América Latina e Caribe, Espanha e Portugal Redalyc. Foram excluídos outros tipos de trabalhos (teses, dissertações, monografias, livros, entrevistas e resenhas), bem como os artigos que se repetiram nas bases. Na busca, utilizamos os seguintes descritores: gênero AND decolonial/pós-colonial; e feminismo decolonial/descolonial/pós-colonial. No portal da CAPES foram encontrados 282 registros e, no Redalyc, 784. Dos 1066 registros levantados, foram removidos 1031 a partir dos critérios de exclusão.

Os critérios de inclusão definidos para seleção dos trabalhos foram: artigos com resumo e texto completo em português ou espanhol, revisados por pares, disponíveis on-line e de forma gratuita, publicados nos últimos dez anos (2008-2018) e que apresentem uma discussão conceitual sobre gênero. O processo resultou na seleção de 35 artigos (listados a seguir), os quais foram analisados na íntegra e identificados quanto às tendências dos argumentos em favor das epistemologias decoloniais de gênero construídas, predominantemente, por teóricas/os latinoamericanas/os. Para análise do material foi utilizada uma matriz para análise bibliográfica dos conceitos de gênero, onde buscamos as definições do conceito, as categorias e/ou elementos para análise e as relações com outros conceitos.

\begin{tabular}{|c|c|c|}
\hline Autor/a & Título & Ano \\
\hline ALMENDRA, Javiera Cubillos & $\begin{array}{l}\text { Reflexiones sobre el proceso de investigación. Una propuesta } \\
\text { desde el feminismo decolonial }\end{array}$ & 2014 \\
\hline BAHRI, Deepika & Feminismo e/no pós-colonialismo & 2013 \\
\hline BALLESTRIN, Luciana & Feminismos Subalternos & 2017 \\
\hline BERNARDINO-COSTA, Joaze & $\begin{array}{l}\text { Decolonialidade e interseccionalidade emancipadora: } \\
\text { a organização política das trabalhadoras domésticas no Brasil }\end{array}$ & 2015 \\
\hline $\begin{array}{l}\text { CABRERA, Marta; MONROY, } \\
\text { Liliana Vargas }\end{array}$ & $\begin{array}{l}\text { Transfeminismo, decolonialidad y el assunto del conocimiento: } \\
\text { inflexiones de los feminismos dissidentes contemporâneos }\end{array}$ & 2014 \\
\hline CARDOSO, Cláudia Pons & Amefricanizando o feminismo: o pensamento de Lélia Gonzalez & 2014 \\
\hline CYPRIANO, Breno & Construções do pensamento feminista latino-americano & 2013 \\
\hline $\begin{array}{l}\text { DIAS, Júlia Machado; } \\
\text { MELLO ARCÂNGELO, Élton de }\end{array}$ & $\begin{array}{l}\text { Feminismo Decolonial e Teoria Queer: limites e possibilidades de } \\
\text { diálogo nas relações internacionais }\end{array}$ & 2017 \\
\hline ESPINOSA-MIÑOSO, Yuderkys & Una crítica descolonial a laepistemología feminista crítica & 2014 \\
\hline FABBRI, Luciano & $\begin{array}{l}\text { Desprendimiento androcéntrico. Pensar la matriz colonial de poder } \\
\text { desde los aportes de Silvia Federici y María Lugones }\end{array}$ & 2014 \\
\hline FALQUET, Jules & $\begin{array}{l}\text { Las feministas autónomas latinoamericanas y caribeñas: veinte } \\
\text { años de dissidências }\end{array}$ & 2014 \\
\hline $\begin{array}{l}\text { FIGUEIREDO, Angela;GOMES, } \\
\text { Patrícia Godinho }\end{array}$ & $\begin{array}{l}\text { Para além dos feminismos: uma experiência comparada entre } \\
\text { Guiné-Bissau e Brasil }\end{array}$ & 2016 \\
\hline $\begin{array}{l}\text { GOMES, Camilla de } \\
\text { Magalhães }\end{array}$ & Gênero como categoria de análise decolonial & 2018 \\
\hline $\begin{array}{l}\text { GOMES, Camilla de } \\
\text { Magalhães }\end{array}$ & $\begin{array}{l}\text { Constituição e feminismo entre gênero, raça e direito: das } \\
\text { possibilidades de uma hermenêutica constitucional } \\
\text { antiessencialista e decolonial }\end{array}$ & 2018 \\
\hline $\begin{array}{l}\text { GOULART ALMEIDA, Sandra } \\
\text { Regina }\end{array}$ & Intervenções feministas: pós-colonialismo, poder e subalternidade & 2013 \\
\hline $\begin{array}{l}\text { LEAL, Maria Lucia; ALCURE, } \\
\text { Adriana Schneider; BACELAR, } \\
\text { Camila Bastos; AZEVEDO, } \\
\text { Maria Thereza }\end{array}$ & Pedagogias feministas e de (s) coloniais nas artes da vida & 2017 \\
\hline
\end{tabular}




\begin{tabular}{|c|c|c|}
\hline LÓPEZ, Laura Cecília & $\begin{array}{l}\text { A mobilização política das mulheres negras no Uruguai. } \\
\text { Considerações sobre interseccionalidade de raça, gênero e } \\
\text { sexualidade }\end{array}$ & 2013 \\
\hline LUGONES, María & Colonialidad y Género & 2008 \\
\hline LUGONES, María & Rumo a um feminismo descolonial & 2014 \\
\hline $\begin{array}{l}\text { MASSON, Sabine; GÓMEZ, } \\
\text { Pilar Castro }\end{array}$ & $\begin{array}{l}\text { Sexo/género, clase, raza: feminismo descolonial frente a la } \\
\text { globalización: Reflexiones inspiradas a partir de la lucha de las } \\
\text { mujeres indígenas en Chiapas }\end{array}$ & 2011 \\
\hline $\begin{array}{l}\text { MAYORGA, Claudia; COURA, } \\
\text { Alba; MIRALLES, Nerea; } \\
\text { CUNHA, Viviane Martins }\end{array}$ & $\begin{array}{l}\text { As críticas ao gênero e a pluralização do feminismo: colonialismo, } \\
\text { racismo e política heterossexual }\end{array}$ & 2013 \\
\hline MEDINA MARTÍN, Rocío & $\begin{array}{l}\text { Feminismos periféricos, feminismos-otros: una genealogía feminista } \\
\text { decolonial por reivindicar }\end{array}$ & 2013 \\
\hline MEDINA MARTíN, Rocío & $\begin{array}{l}\text { Mujeres Saharauis, Colonialidad del Género y Nacionalismos: un } \\
\text { acercamiento a partir de los feminismos decoloniales }\end{array}$ & 2014 \\
\hline PELÚCIO, Larissa & $\begin{array}{l}\text { Subalterno quem, cara pálida? Apontamentos às margens sobre } \\
\text { pós-colonialismos, feminismos e estudos queer }\end{array}$ & 2012 \\
\hline PÉREZ FLORES, Larisa & $\begin{array}{l}\text { Cuerpos y desplazamientos. Retos feministas en un marco } \\
\text { pos/decolonial }\end{array}$ & 2015 \\
\hline PÉREZ, Mariana Noel Guerra & $\begin{array}{l}\text { Notas desde los feminismos del sur: justicia y subversión } \\
\text { semiótica-epistemológica-política }\end{array}$ & 2018 \\
\hline $\begin{array}{l}\text { ROSA, Alexandre Reis; } \\
\text { MEDEIROS, Cintia Rodrigues } \\
\text { de Oliveira; VALADÃO } \\
\text { JÚNIOR, Valdir Machado }\end{array}$ & $\begin{array}{l}\text { Sob as sombras do discurso colonial: subalternidade e } \\
\text { configurações de gênero em uma lavanderia do interior de } \\
\text { Minas Gerais }\end{array}$ & 2012 \\
\hline RUIZ, Salomé Carvajal & $\begin{array}{l}\text { Una experiencia estudiantil y colectiva de investigación feminista } \\
\text { decolonial en la Universitat de València. Trayectorias } \\
\text { epistémicas y metodológicas }\end{array}$ & 2017 \\
\hline $\begin{array}{l}\text { SANTOS, Gustavo Gomes da } \\
\text { Costa; SILVA, Marcos de } \\
\text { Araújo }\end{array}$ & $\begin{array}{l}\text { Gênero, sexualidade e pós-colonialidade: Apontamentos para uma } \\
\text { agenda de pesquisa }\end{array}$ & 2014 \\
\hline SANTOS, Luciane Lucas dos & $\begin{array}{l}\text { Deve a economia feminista ser pós-colonial? Colonialidade } \\
\text { económica, género e epistemologias do Sul }\end{array}$ & 2017 \\
\hline TORRES, Catherine Moore & $\begin{array}{l}\text { Feminismos del Sur, abriendo horizontes de descolonización. } \\
\text { Los feminismos indígenas y los feminismos comunitários }\end{array}$ & 2018 \\
\hline $\begin{array}{l}\text { TOVAR-HERNÁN, Deysy } \\
\text { Margarita; GUERRERO, Olivia } \\
\text { Tena }\end{array}$ & Mujeres nahuas: desapropriando la condición masculina & 2017 \\
\hline $\begin{array}{l}\text { TRUJILLO CRISTOFANINI, } \\
\text { Macarena;HERNÁNDEZ, Paola } \\
\text { Contreras }\end{array}$ & $\begin{array}{l}\text { Desde las epistemologías feministas a los feminismos decoloniales: } \\
\text { Aportes a los estudios sobre migraciones }\end{array}$ & 2017 \\
\hline $\begin{array}{l}\text { TRUJILLO CRISTOFANINI, } \\
\text { Macarena; RIVERA VARGAS, } \\
\text { Pablo; SARAMANCH, Elisabet } \\
\text { Almeida }\end{array}$ & $\begin{array}{l}\text { Desde el conocimiento situado hacia el feminismo decolonial. } \\
\text { Nuevas perspectivas de análisis para el estudio de la } \\
\text { monomarentalidad e inmigración latino-americana }\end{array}$ & 2015 \\
\hline VILLARROEL PEÑA, Yetzy Urimar & $\begin{array}{l}\text { Feminismos descoloniales latinoamericanos: geopolítica, } \\
\text { resistencia y Relaciones Internacionales }\end{array}$ & 2018 \\
\hline
\end{tabular}




\section{Resultados e discussão}

\section{Caracterização geral do material bibliográfico}

Os artigos recuperados foram observados em termos de autoria, nacionalidade, local de publicação, ano e tipo de estudo (teórico ou empírico). A partir da categorização, é possível notar que trabalhos latino-americanos de diversos países começam a ganhar visibilidade. As vozes femininas são grande maioria nesses estudos, tal como acontece nos estudos feministas em geral. Nota-se expressiva participação de autoras/es brasileiras/os ( $42 \%$ aproximadamente). Percebemos que esses conhecimentos têm extrapolado as fronteiras da América Latina e alçado os países do Norte, levando novas perspectivas críticas à teoria social.

Em relação à formação acadêmica das/os estudiosas/os, observamos a pluralidade de pesquisadoras/es de diversos campos das Ciências Humanas e Sociais que se voltam para uma análise decolonial de gênero com o intuito de pensar estratégias de resistência e de enfrentamento às formas coloniais instituídas. Dentre essas, temos a presença marcante de investigadoras/es das Ciências sociais (09). Em seguida, Filosofia (05), Direito (04), Ciências políticas (03), Letras/Literatura (03), Psicologia (03), Relações internacionais (03), Antropologia (02), Comunicação social (02), História (02), Administração (01), Artes cênicas (01), Economia (01), Pedagogia (01) e Serviço social (01).

Em relação aos artigos publicados no Brasil, nota-se a importância do periódico Revista Estudos Feministas na divulgação nacional dessa discussão, bem como na tradução para o português de textos clássicos do campo. A revista está vinculada à Universidade Federal de Santa Catarina e é um dos mais antigos e relevantes periódicos no campo dos estudos feministas e de gênero do país.

Quanto à natureza dos estudos, há uma quantidade considerável de artigos de discussão teórica, aproximadamente $75 \%$ dos achados. Ainda são incipientes as aplicações desse conteúdo em pesquisas empíricas. Contudo, é uma discussão bastante recente que começa a ganhar notoriedade a partir da popularização das publicações da filósofa argentina María Lugones, principal expoente do feminismo decolonial. Destaca-se em sua obra o conceito de colonialidade de gênero, ideia que está presente na maioria dos artigos recuperados. Lugones também é utilizada nas discussões sobre as políticas de raça, gênero e colonialidade, bem como da construção moderna/colonial do sistema de gênero.

\section{Contribuições do pensamento decolonial aos estudos de gênero}

"Quem pode falar e por quem?", "Quem ouve?" e "Como se representa a si e os outros?" são importantes questões levantadas por Deepika Bahri (2013, p. 660) e que estão no centro das discussões contra-hegemônicas do feminismo. A emergência dos feminismos decoloniais está atrelada ao questionamento de análises, propostas metodológicas e projetos políticos dos movimentos feministas a partir dos anos 1960 e 1970, momento em que as lutas sociais e as denúncias contra a violenta e racista epistemologia moderna ganham força, sustentadas na crítica de que não contemplavam e, de certo modo, ainda não contemplam, questões como raça, classe, gênero e práticas sexuais dissidentes. Neste momento, tem-se o gradual aparecimento dos movimentos descritos por Rocío Medina Martín (2013) como "feminismos periféricos, feminismos-otros", ou, ainda, "feminismos subalternos", nos termos de Ballestrin (2017), para tratar do que está à margem do pensamento ocidental e sua episteme colonial: o feminismo do terceiro mundo, ecofeminismo, feminismo antiimperialista e anticapitalista, feminismo lésbico, feminismo negro, feminismo chicano, feminismo pós-colonial, feminismo decolonial, feminismo indígena, feminismo comunitário, dentre outros.

Todas essas diferentes correntes de pensamento parecem concordar com o caráter subalterno imposto a certos grupos sociais, deixando-os de fora do pensamento feminista eurocêntrico (MARTíN, 2013). Essas teorias cumprem uma dupla ação política de questionar a invisibilização das várias formas de expressão do ser mulher e, ainda, denunciam o elitismo do feminismo hegemônico, caracterizado como: "ocidental, branco, universalista, eurocêntrico e de Primeiro Mundo" (BALLESTRIN, 2017, p. 1036). Contudo, neste trabalho, o foco será lançado nos feminismos decoloniais.

No desenvolvimento da teoria feminista hegemônica há a tendência a estereotipar ou generalizar as mulheres em um sujeito monolítico singular (BAHRI, 2013). Sustentou-se a ideia da universalidade da dominação patriarcal e de gênero, na qual todas as mulheres são afetadas da mesma maneira, como se a história fosse uma, no singular, tendo como sujeito um ser abstrato, geográfica e historicamente descontextualizado (BALLESTRIN, 2017). Tal compreensão tem justificado seu uso e manejo indiscriminado em diferentes contextos. Todavia, em se tratando de gênero, os feminismos subalternos denunciam a falácia da universalidade e apontam as diferentes formas de experienciar o ser mulher, incluindo em suas análises as relações de poder, classe, raça/etnia, geração, territórios, (inter)nacionalidade, dentre outros (Gustavo Gomes da Costa SANTOS; Marcos de Araújo SILVA, 2014). O termo mulher, nesse sentido, por si só, não tem um significado essencial ou, quando tem, adquire um significado racista, uma vez que a lógica categórica selecionou 
historicamente apenas o grupo dominante como sua norma: as mulheres burguesas heterossexuais brancas (LUGONES, 2008). Sendo assim, entendemos que há uma multiplicidade de lugares e modos de enunciação (ou de silêncio) que revelam a diversidade de fatores que forjam uma cadeia de violências que afetam diferentemente as diferentes mulheres.

Por outro lado, os teóricos comprometidos com a crítica colonial e seus saberes deram pouca importância às temáticas de gênero e sexualidade, em especial à questão das mulheres (Larissa PELÚCIO, 2012; MARTíN, 2013). Tendo em perspectiva os processos de colonização que ocorreram na América, Larisa Pérez Flores (2015) destaca um aspecto despercebido nos estudos decolonialistas:

No fue el "ser humano" blanco quien trazó la línea del ser, ni quien colonizó América y el Caribe. Fue el "hombre blanco". Y fue "la otredad" de su "masculinidad blanca" la silenciada por las diversas instituciones, incluida la ciencia (FLORES, 2015, p. 106).

Em outras palavras, a patriarcalidade se reproduz na teoria decolonial. Ao enfocar a raça como elemento central em suas teorizações, muitos estudiosos limitam o foco de suas análises e desconsideram o papel que o gênero ocupa nas experiências de colonialidade. Neste sentido, surge a necessidade de produzir epistemologias feministas no contexto latino-americano a partir de suas heterogeneidades e complexidades.

O feminismo decolonial, segundo Gabriel de Sena Jardim e Cláudio de São Thiago Cavas (2017, p. 73), "indica um outro caminho possível propondo analisar a opressão de gênero e raça a partir de uma epistemologia de fronteira". Além disso, "promove a crítica contra a universalidade imposta pela modernidade colonial, reivindicando intersecções de gênero, raça, classe e sexualidade na epistemologia feminista" (JARDIM; CAVAS, 2017, p. 87). O sistema colonial de gênero foi inicialmente criticado por Lugones (2008) e, a partir disso, muita discussão passou a ser feita em relação à combinação entre raça, gênero, sexualidade e classe. Lugones se inspirou no conceito de interseccionalidade defendido pela feminista afro-americana Kimberlé Crenshaw (2002). Essa ideia implica

uma conceituação do problema que busca capturar as consequências estruturais e dinâmicas da interação entre dois ou mais eixos da subordinação. Ela trata especificamente da forma pela qual o racismo, o patriarcalismo, a opressão de classe e outros sistemas discriminatórios criam desigualdades básicas que estruturam as posições relativas de mulheres, raças, etnias, classes e outras (CRENSHAW, 2002, p. 177).

Tal perspectiva aposta no entrecruzamento das múltiplas categorias geradoras de opressão, uma vez que tais categorias identitárias de diferenciação social não existem de forma isolada e nem a priori (Mara Lucia LEAL; Adriana Schneider ALCURE; Camila Bastos BACELAR; Maria Thereza AZEVEDO, 2017). A expressão das desigualdades de gênero dependerá da sobreposição de diferentes níveis e contextos de opressão, já que por meio da interação entre as várias formas de produção de desigualdades é que essas experiências se materializam nos corpos dos sujeitos (Luciane Lucas dos SANTOS, 2017).

Apesar desses avanços, o conceito de interseccionalidade tem sofrido algumas críticas. Sobre isso, Danièle Kergoat (2010, p. 93) comenta: "interseccionalidade é um instrumento de análise que coloca as relações em posições fixas, que divide as mobilizações em setores, exatamente da mesma maneira pela qual o discurso dominante naturaliza e enquadra os sujeitos em identidades previamente definidas". Para a autora, as relações sociais são consubstanciais e coextensivas, ou seja, são indissociáveis nas práticas sociais e se reproduzem e se coproduzem reciprocamente, conforme apregoa o materialismo histórico-dialético. Neste sentido, as relações sociais de gênero, classe e raça são consubstanciais e coextensivas, isto é, devemos pensá-las como causa e efeito, concomitantemente. Em outras palavras, o modo como entendemos gênero está condicionado à forma como vemos a raça e a classe, e vice-versa.

Esta perspectiva parece concordar com os apontamentos de Lugones (2008) sobre a colonialidade de gênero. Para a autora, gênero, raça e classe têm sido apontadas como categorias e, como tais, presas a binarismos: homem/mulher, branca/negra, burguês/proletário. Neste sentido, ao analisar as categorias, esconde-se a intersecção entre elas. Todavia, cabe ressaltar que a leitura de interseccionalidade de Lugones difere da defendida por Crenshaw, uma vez que aquela aponta o limite do conceito."En la intersección entre 'mujer' y 'negro' hay una ausencia donde debería estar la mujer negra precisamente porque ni 'mujer' ni 'negro' la incluyen. La intersección nos muestra un vacío", defende Lugones (2008, p. 82). Em outro texto, comenta: "a lógica categorial moderna constrói as categorias em termos homogêneos, atomizados, separáveis, e constituídos dicotomicamente" (LUGONES, 2014, p. 942). Djamila Ribeiro (2016) nos convida a reposicionar a questão da interseccionalidade, evitando a fragmentação de categorias que são inseparáveis:

Pensar a interseccionalidade é perceber que não pode haver primazia de uma opressão sobre as outras e que, sendo estas estruturantes, é preciso romper com a estrutura. É pensar que raça, classe e gênero não podem ser categorias pensadas de forma isolada, mas sim de modo indissociável (RIBEIRO, 2016, p. 101). 
Javiera Cubillos Almendra (2014) insiste, a partir das ideias de Lugones, na radicalização do feminismo por meio da compreensão de que marcadores como raça, classe, gênero, são variáveis coconstitutivas, ou seja, são elementos que estão inscritos uns nos outros e não podem ser pensados de forma separada. São produzidos na relação com os outros e se articulam e reforçam outros sistemas de dominação. Contudo, conforme apontado anteriormente, a raça tem um papel fundante na lógica da colonialidade do poder e, consequentemente, tem ordenado mais fortemente as relações de gênero na produção de subalternidades e subjetividades femininas estigmatizadas. Raça e gênero são signos que dão significado aos corpos e, sob o viés da colonialidade, legitimam a dicotomia humano/não humano ao reposicionar as relações de superioridade e inferioridade entre o homem ocidental e as/os colonizadas/os. Neste sentido, os europeus introduziram uma dicotomia racial que sustenta um racismo desumanizador que nega a determinados corpos o componente construído, histórico, cultural, relacional, tornando-os meros objetos sujeitos à ação normatizadora racional-moderna-colonial (LUGONES, 2008; 2014; Camilla de Magalhães GOMES, 2018a).

A estrutura de poder que ordena toda a existência social, conforme Quijano (2005), cria um sistema de relações de dominação, exploração e conflito entre atores sociais de todo o planeta, que lutam pelo controle dos quatros âmbitos fundamentais da existência humana, quais sejam: sexo, trabalho, intersubjetividade e autoridade coletiva, seus recursos e produtos. Neste esquema, o atual padrão de poder é o primeiro na história a articular em instituições cada um dos âmbitos da existência social, num esforço de naturalização das relações sociais, sendo eles interdependentes entre si, configurando-se como um sistema que abarca a totalidade da população do planeta. Como destaca Quijano (2005, p. 113):

Assim, no controle do trabalho, de seus recursos e de seus produtos, está a empresa capitalista; no controle do sexo, de seus recursos e produtos, a família burguesa; no controle da autoridade, seus recursos e produtos, o Estado-nação; no controle da intersubjetividade, o eurocentrismo.

Esta lógica axial expressa uma inter-relação, onde os elementos moldam e são moldados pelas formas que as relações do poder tomam. Nessa lógica, as lutas pelo controle do sexo, seus recursos e seus produtos definem para o autor o lugar do sexo/gênero em sua teoria.

Entretanto, segundo Lugones (2008), Quijano discorre com base em uma compreensão patriarcal e heteronormativa das disputas pelo controle do sexo. Ao utilizar a categoria "sexo" para analisar as relações entre mulheres e homens, o autor reforça um determinismo biológico que coloca as diferenças percebidas em uma posição essencialista, natural, que, sob o signo dos genitais, cria um esquema hierárquico onde o feminino está atrelado à inferioridade, obscurecendo, assim, a construção histórico-social do gênero (GOMES, 2018b). Essa lógica é baseada em uma compreensão capitalista, eurocentrada e global de gênero, que invisibiliza o modo pelo qual as mulheres colonizadas e não brancas foram subordinadas e desprovidas de poder. Além disso, Lugones (2008) pontua que a definição de um sistema de gênero é anterior à interpretação baseada em características biológicas socialmente atribuídas ao homem e à mulher, ou seja, constrói-se uma normativa de gênero e, em seguida, aplica-se aos corpos.

Por outro lado, ao transpor noções de patriarcado e homofobia para territórios periféricos, não europeus, como se existissem ou sempre houvesse existido em todos os espaços e tempos históricos, reforça-se um discurso colonial, pois se invisibiliza outras formas de relações (PELúCIO, 2012). A violência colonizadora fez e faz desaparecer outros fazeres do gênero, pois o arsenal racista da colonialidade reduz tudo o que difere da norma à animalidade, visando à domesticação das condutas desviantes que escapam ao projeto de modernidade (GOMES, 2018a).

Neste sentido, Gomes (2018b, p. 70) indaga se não seria o próprio sistema de gênero uma imposição moderna e ocidental, pois estudos para além do Norte Global mostram que "povos originários, povos indígenas, grupos sociais e comunitários colonizados não possuíam (ou ainda não possuem) uma estrutura de gênero como a que se imprimiu na colônia pela metrópole". Esses povos se organizam segundo outras cosmologias, outros pressupostos ontológicos, com papéis de gênero mais transitórios e fluidos, com uma divisão de tarefas que diverge da divisão sexual do trabalho, com maior abertura à homossexualidade, com identidades que diferem ou escapam do binômio mulher-homem, ou, mesmo, sem um sistema de gênero institucionalizado (LUGONES, 2008; GOMES, 2018b).

No entanto, com os processos de dominação colonial, observa-se a transformação da vida dos povos tradicionais e, consequentemente, a inferiorização das mulheres. O colonizador branco, ao invadir esses espaços, traz consigo uma forma específica de relação social que induz os homens colonizados a ocuparem papéis patriarcais (LUGONES, 2008). O machismo aparece nas comunidades como um mecanismo compensatório fruto da opressão racial. Assim, o gênero masculino se constitui à custa do gênero feminino e cria as condições materiais necessárias para a sujeição das mulheres aos homens (Luciano FABBRI, 2014).

Com relação à dinâmica entre as diferentes mulheres, devemos lembrar que as lutas sociais das feministas brancas pelo acesso ao mercado de trabalho e avanço dos direitos civis foi, em 
parte, sustentada pela exploração das mulheres negras, latinas e indígenas dentro de seus países (MEDINA MARTíN, 2014). Raça e gênero foram construtos coloniais impostos com o objetivo de racializar e engendrar as sociedades colonizadas visando à reprodução de um ethos europeu que se mantém até os dias atuais (BALLESTRIN, 2017). Ou seja, o feminismo eurocentrado traz um modelo específico de mulher enquanto sujeito político, mas invisibiliza uma série de sujeições que ocorreram entre as diferentes mulheres para que um determinado grupo conquistasse certo "empoderamento".

Entretanto, o feminismo decolonial critica o fatalismo e a visão das mulheres latinoamericanas como tão somente vítimas da opressão e da invisibilidade, pois as relações sociais não são estáticas e unidirecionais, ao contrário, estão em constante movimento. Essa dinâmica cria também estratégias de resistência na medida em que nos diferenciamos daquilo que é hegemônico (LUGONES, 2014). Cabe pensar, então, os sujeitos do feminismo como agentes de libertação, emancipação e transformação, capazes de resistir e romper com a herança colonial.

Assim, o feminismo decolonial propõe um retorno aos contextos locais visando à reinterpretação da história para entender o racismo estrutural enraizado nas instituições e na subjetividade. Suas principais contribuições residem em apontar gênero como uma categoria não essencializada, relacional, racializada, situada histórica e geograficamente; revelar que a colonialidade de gênero ainda persiste na atualidade em práticas cotidianas e que é possível recriar e subverter fronteiras instituídas, "elaborando uma genealogia de pensamento crítico a partir das periferias, das margens; um feminismo antirracista de origem latina para desmantelar a matriz da opressão eurocêntrica" (Stela FISCHER, 2017, p. 2).

\section{Considerações finais}

Historicamente, gênero tem sido usado como sistema de classificação e hierarquização da população com o intuito de atender aos poderes dominantes e ao seu ideal de modernidade, em detrimento das práticas solidárias e resistências comunitárias. A norma hegemônica de gênero diz da colonialidade que opera de forma insidiosa e hierarquizante entre as diferentes culturas, fazendo com que algumas sejam desqualificadas. Tem-se, dessa forma, o apagamento de certos modos de organização social, representações e sistemas simbólicos e a tradução das experiências desviantes em termos coloniais. É necessário, portanto, historicizar o patriarcado e renunciar à crença na organização das relações sociais baseadas no dimorfismo biológico e em uma heterossexualidade normativa, para enxergar formas outras de estar no mundo e se relacionar, para além da lógica categorial e dicotômica do sistema moderno colonial de gênero (LUGONES, 2008; 2014).

O feminismo decolonial ressalta que, por meio dos processos de colonização, as mulheres da América Latina não foram apenas colonizadas, mas também foram racializadas. A colonialidade, sustentada na ideia de raça, cria distintos corpos e, consequentemente, distintas formas de experienciar esses corpos. Esses corpos, pensados como territórios políticos, carregam as dores e os paradoxos dessas marcas culturais que forjam diferentes experiências, mas, também, conjugam as mais diversas estratégias de enfrentamento. A denúncia das diversas opressões que recaem sobre o corpo das mulheres latino-americanas e suas experiências, assim como as diversas relações de poder que sustentam esses papéis de gênero, guarda uma dimensão política importante. Desse modo, consideramos que esta perspectiva traz novos e importantes tensionamentos para pensar as questões acerca das mulheres quilombolas da América Latina residentes no meio rural enquanto sujeitos políticos dotados de uma particularidade histórica e de agência libertadora.

A discussão sobre gênero em uma perspectiva decolonial vem se fortalecendo nos últimos anos nas mais diversas áreas do conhecimento, especialmente no Brasil, mas ainda demanda esforços de teóricas/os da América Latina em pensar as heranças e marcas da colonialidade na atualidade. Contudo, enquanto as Ciências Sociais vêm contribuindo significativamente nessa discussão, outros campos de saberes, tal como a Psicologia, ainda não incorporaram esse debate de maneira contundente. Isso alerta para a (re)produção de muitos estereótipos de gênero e saberes coloniais na formação e práticas da Psicologia.

Faz-se necessário, portanto, esforços para uma descolonização epistêmica. No âmbito acadêmico, esse esforço implica a invenção contínua de novos conceitos, no manejo de diferentes concepções de subjetividade e o uso de metodologias que problematizem as narrativas pretensamente universalizantes, as formas hegemônicas de ver e representar o outro e favoreçam uma inquietação permanente atenta ao presente. A investigação feminista de cunho decolonial, neste sentido, se apresenta como ato ético-político capaz de desestabilizar as formas consensuais de produção do conhecimento e de nos reposicionar na direção do que Friedrich Nietzsche (1992) chamou por perspectivismo, ou seja, compreender que na vida não há fatos, apenas interpretações. 


\section{Referências}

ALMEIDA, Eliene Amorim; SILVA, Janssen Felipe da. "Abya Yala Como Território Epistêmico: Pensamento Decolonial Como Perspectiva Teórica". Revista Interritórios, Caruaru, v. 1, n. 1, p. 42-64, 2015. Disponível em https://periodicos.ufpe.br/revistas/interritorios/article/view/5009. Acesso em 20/03/2018.

ALMENDRA, Javiera Cubillos. "Reflexiones sobre el proceso de investigación. Una propuesta desde el feminismo decolonial". Athenea Digital, Barcelona, v. 14, n. 4, p. 261-285, out./dez. 2014. Disponível em https://www.raco.cat/index.php/Athenea/article/view/292060. Acesso em 18/04/2018.

ALVES, Cândida Beatriz; DELMONDEZ, Polianne. "Contribuições do Pensamento Pós-Colonial à Psicologia Política". Psicologia Política, São Paulo, v. 15, n. 34, p. 647-661, 2015. Disponível em http://pepsic.bvsalud.org/scielo.php?script=sci_arttext\&pid=S1519-549X2015000300012. Acesso em 20/03/2018.

BAHRI, Deepika. "Feminismo e/no pós-colonialismo". Revista Estudos Feministas, Florianópolis, v. 21 , n. 2, p. 659-688, 2013. Disponível em https://dx.doi.org/10.1590/\$0104-026X2013000200018. Acesso em 06/03/2018.

BALLESTRIN, Luciana. "América Latina e o giro decolonial". Revista Brasileira de Ciência Política, Brasília, v. 11, p. 89-117, maio/ago. 2013. Disponível em http://www.scielo.br/scielo.php?pid=S0103$33522013000200004 \&$ script $=$ sci_arttext\&tlng=es. Acesso em 18/03/2018.

BALLESTRIN, Luciana. "Feminismos Subalternos". Revista Estudos Feministas, Florianópolis, v. 25, n. 3, p. 1035-1054, set.-dez. 2017. Disponível em http://www.scielo.br/scielo.php?script=sci_arttext\&pid=SO 104-026X2017000301035. Acesso em 20/03/2018.

CARBONIERI, Divanize. "Pós-colonialidade e decolonialidade: rumos e trânsitos". Revista Labirinto, Porto Velho, v. 24, n. 1, p. 280-300, jan.-jun. 2016. Disponível em http://www.periodicos.unir.br/ index.php/LABIRINTO/article/view/1746. Acesso em 18/03/2018.

CRENSHAW, Kimberlé. "Documento para o encontro de especialistas em aspectos da discriminação racial relativos ao gênero". Revista Estudos Feministas, Florianópolis, v. 10, n. 1, p. 171-188, jan. 2002. Disponível em http://www.scielo.br/scielo.php?pid=S0104-026X200200010001 1 \&script=sci_abstract \&tIng=pt. Acesso em 15/05/2018.

FABBRI, Luciano. "Desprendimiento androcéntrico. Pensar la matriz colonial de poder desde los aportes de Silvia Federici y María Lugones". Universitas Humanística, Bogotá, v. 78, p. 89-107, jul.-dez. 2014. Disponível em http://www.scielo.br/scielo.php?pid=S0104-026X200200010001 1 \&script=sci_abstract \&tIng=pt. Acesso em 15/04/2018.

FANON, Frantz. Pele negra, máscaras brancas. Salvador: EDUFBA, 2008.

FAUSTINO, Deivison Mendes. "Colonialismo, racismo e luta de classes: a atualidade de Frantz Fanon". In: V SIMPÓSIO INTERNACIONAL LUTAS SOCIAIS NA AMÉRICA LATINA. "REVOLUÇÕES NAS AMÉRICAS: PASSADO, PRESENTE E FUTURO". Anais... Londrina, 2013, p. 216-232. Disponível em http:/ /www.uel.br/grupo-pesquisa/gepal/v16_deivison_Gl.pdf. Acesso em 29/08/2018.

FISCHER, Stela. "Mulheres, performance e ativismo feministas decoloniais". In: SEMINÁRIO INTERNACIONAL FAZENDO GÊNERO 11 \& 13th WOMEN'S WORLDS CONGRESS, 2017. Florianópolis, UFSC. Anais... Florianópolis: UFSC/Instituto de Estudos de Gênero, 2017. p. 1-10. Disponível em http://www. wwc2017.eventos.dype.com.br/resources/anais/1498851059_ARQUIVO_Fazendo_Genero_2017.pdf. Acesso em 19/07/2019.

GOMES, Camilla de Magalhães. "Constituição e feminismo entre gênero, raça e direito: das possibilidades de uma hermenêutica constitucional antiessencialista e decolonial". Revista História: Debates e Tendências, Passo Fundo, v. 18, n. 3, p. 343-365, 2018a.

GOMES, Camilla de Magalhães. "Gênero como categoria de análise decolonial". Civitas-Revista de Ciências Sociais, Porto Alegre, v. 18, n. 1, p. 65-82, jan.-abr. 2018b. Disponível em http://www.scielo.br/ scielo.php?script=sci_arttext\&pid=S1519-60892018000100065\&lng=en\&nrm=iso\&tlng=pt. Acesso em 26/08/2018.

JARDIM, Gabriel de Sena; CAVAS, Claudio São Thiago. "Pós-colonialismo e feminismo decolonial: caminhos para uma compreensão anti-essencialista do mundo". Ponto-e-Vírgula: Revista de Ciências Sociais, São Paulo, v. 22, p. 73-91, jul.-dez. 2017. Disponível em https://revistas.pucsp.br/ pontoevirgula/article/view/33335. Acesso em 19/07/2019. 
KERGOAT, Danièle. "Dinâmica e consubstancialidade das relações sociais". Novos estudos CEBRAP, São Paulo, n. 86, p. 93-103, mar. 2010. Disponível em http://www.scielo.br/scielo.php?script=sci_arttext \&pid=S0101-33002010000100005. Acesso em 19/07/2018.

LEAL, Mara Lucia; ALCURE, Adriana Schneider; BACELAR, Camila Bastos; AZEVEDO, Maria Thereza. "Pedagogias feministas e de(s)coloniais nas artes da vida". OuvirOUver, Uberlândia, v. 13, n. 1, p. 24-39, 2017 . Disponível em http://www.seer.ufu.br/index.php/ouvirouver/article/view/36982. Acesso em 19/04/2018.

LUGONES, María. “Colonialidad y Género”. Tabula rasa, Bogotá, v. 9, p. 75-101, jul.-dez. 2008. Disponível em http://www.revistatabularasa.org/numero-9/05lugones.pdf. Acesso em 03/04/2018.

LUGONES, María. "Rumo a um feminismo descolonial". Revista Estudos Feministas, Florianópolis, v. 22, n. 3, p. 935-952, set.-dez. 2014. Disponível em http://www.redalyc.org/articulo.oa?id=38132698013. Acesso em 03/04/2018.

MACIAZEKI-GOMES, Rita de Cássia; NOGUEIRA, Conceição; TONELI, Maria Juracy. "Mulheres em contextos rurais: um mapeamento sobre gênero e ruralidade". Psicologia \& Sociedade, Belo Horizonte, v. 28, n. 1, p. 115-124, jan.-abr. 2016. Disponível em http://www.scielo.br/scielo.php?script=sci_arttext \&pid=S0102-718220160001001 15\&lng=en\&nrm=iso\&tlng=pt. Acesso em 03/08/2018.

MARTINS, Paulo Henrique; BENZAQUEN, Júlia Figueredo. "Uma proposta de matriz metodológica para os estudos descoloniais". Revista Cadernos de Ciências Sociais da UFRPE, Recife, v. 2, n. 11, p. 10-31, ago-dez. 2017. Disponível em http://www.journals.ufrpe.br/index.php/cadernosdecienciassociais/ article/view/1882. Acesso em 05/03/2018.

MEDINA MARTíN, Rocío. "Feminismos periféricos, feminismos-otros: una genealogía feminista decolonial por reivindicar". Revista internacional de pensamiento político, Huelva, v. 8, p. 53-79, 2013. Disponível em http://rabida.uhu.es/dspace/handle/10272/8221. Acesso em 03/04/2018.

MEDINA MARTíN, Rocío. "Mujeres Saharauis, Colonialidad del Género y Nacionalismos: un acercamiento a partir de los feminismos decoloniales". Relaciones Internacionales, Madrid, v. 27, p. 13-34, 2014.

NIETZSCHE, Friedrich. Além do Bem e do Mal: Prelúdio a uma Filosofia do Futuro. São Paulo: Companhia das Letras, 1992. (Obra originalmente publicada em 1887)

PELÚCIO, Larissa. "Subalterno quem, cara pálida? Apontamentos às margens sobre póscolonialismos, feminismos e estudos queer". Contemporânea - Revista de Sociologia da UFSCar, São Carlos, v. 2, n. 2, p. 395-418, 2012. Disponível em http://www.contemporanea.ufscar.br/index.php/ contemporanea/article/view/89/54. Acesso em 05/05/2018.

PÉREZ FLORES, Larisa. "Cuerpos y desplazamientos. Retos feministas en un marco pos/decolonial". Cuadernos Intercambio sobre Centroamérica y el Caribe, San José, v. 12, n. 1, p. 97-115, 2015. Disponível em https://dialnet.unirioja.es/servlet/articulo?codigo=5088964. Acesso em 28/04/2018.

PISCITELLI, Adriana. "Atravessando fronteiras: teorias pós-coloniais e leituras antropológicas sobre feminismos, gênero e mercados do sexo no Brasil". Revista Semestral do Departamento e do Programa de Pós-Graduação em Sociologia da UFSCar, São Carlos, v. 3, n. 2, p. 377-404, 2013. Disponível em http://www.contemporanea.ufscar.br/index.php/contemporanea/article/view/160. Acesso em 05/05/2018.

QUIJANO, Aníbal. "Colonialidade do poder, eurocentrismo e América Latina". In: LANDER, Edgardo (Org.). A colonialidade do saber: eurocentrismo e ciências sociais. Buenos Aires: CLACSO, 2005. p. 107-130.

RIBEIRO, Djamila. "Feminismo Negro para um novo marco civilizatório". SUR 24, v. 13, n. 24, p. 99104, dez. 2016. Disponível em https://sur.conectas.org/wp-content/uploads/201 7/02/9-sur-24-pordjamila-ribeiro.pdf. Acesso em 21/07/2019.

SANTOS, Boaventura de Sousa. "Para além do Pensamento Abissal: das linhas globais a uma ecologia de saberes". In: SANTOS, Boaventura de Sousa; MENESES, Maria Paula (Orgs.). Epistemologias do Sul. Coimbra: Almedina, 2009. p. 23-71.

SANTOS, Gustavo Gomes da Costa; SILVA, Marcos de Araújo. "Gênero, sexualidade e póscolonialidade: Apontamentos para uma agenda de pesquisa". Revista de Estudos AntiUtilitaristas 
e PosColoniais, Recife, v. 4, n. 1, p. 5-19, 2014. Disponível em https://periodicos.ufpe.br/revistas/ realis/article/view/8805. Acesso em 15/04/2018.

SANTOS, Luciane Lucas dos. "Deve a economia feminista ser pós-colonial? Colonialidade económica, género e epistemologias do Sul". Revista Crítica de Ciências Sociais, Coimbra, n. 114, p. 161-186, 2017. Disponível em https://journals.openedition.org/rccs/6797. Acesso em 15/04/2018.

SOUZA, Marcela Tavares de; SILVA, Michelly Dias da; CARVALHO, Rachel de. "Revisão integrativa: 0 que é e como fazer". Einstein (São Paulo), São Paulo, v. 8, n. 1, p. 102-106, 2010. Disponível em hitp:/ /www.scielo.br/scielo.php?pid=S1679-45082010000100102\&script=sci_arttext\&tlng=pt. Acesso em 20/06/2018.

Magda Dimenstein (magda@ufrnet.br) é Professora Titular do Departamento de Psicologia da Universidade Federal do Rio Grande do Norte, bolsista de produtividade 1A/CNPq.

Gabriel de Nascimento e Silva (gablex@ufrn.edu.br) é graduando do Curso de Psicologia da Universidade Federal do Rio Grande do Norte, bolsista PIBIC/CNPq.

Candida Dantas (ufrn00820@ufrn.edu.br) é doutora em Psicologia Social - UFRN. Professora Adjunta do Departamento de Psicologia - UFRN.

João Paulo Macedo (jpmacedo@ufpi.edu.br) é doutor em Psicologia Social - UFRN. Professor Adjunto do Departamento de Psicologia - UFPI, bolsista de produtividade CNPq.

Jáder Ferreira Leite (ufrn01978@ufrn.edu.br) é doutor em Psicologia Social - UFRN. Professor Associado do Departamento de Psicologia - UFRN.

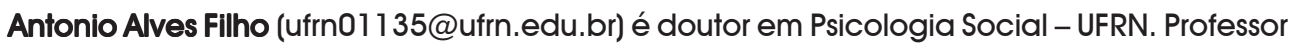
Adjunto do Departamento de Administração - UFRN.

\section{COMO CITAR ESSE ARTIGO DE ACORDO COM AS NORMAS DA REVISTA}

DIMENSTEIN, Magda; SILVA, Gabriel de Nascimento e; DANTAS, Candida; MACEDO, João Paulo; LEITE, Jáder Ferreira; ALVES FILHO, Antonio. "Gênero na perspectiva decolonial: revisão integrativa no cenário latinoamericano". Revista Estudos Feministas, Florianópolis, v. 28, n. 3, e61905, 2020.

\section{CONTRIBUIÇÃO DE AUTORIA}

Magda Dimenstein - Concepção, análise de dados, elaboração do manuscrito, redação, discussão de resultados.

Gabriel de Nascimento e Silva - Concepção, coleta de dados e análise de dados, elaboração do manuscrito, redação, discussão de resultados.

Candida Dantas - Análise de dados, elaboração do manuscrito, redação, discussão de resultados.

João Paulo Macedo - Análise de dados, redação, discussão de resultados.

Jáder Ferreira Leite - Análise de dados, elaboração do manuscrito, redação, discussão de resultados.

Antonio Alves Filho - Análise de dados, redação, discussão de resultados.

\section{FINANCIAMENTO}

Financiada pela Chamada Pública Universal 01/2016 do Conselho Nacional do Desenvolvimento Científico e Tecnológico/CNPq.

CONSENTIMENTO DE USO DE IMAGEM

Não se aplica.

APROVAÇÃO DE COMITÊ DE ÉTICA EM PESQUISA

Não se aplica. 
MAGDA DIMENSTEIN ET AL.

CONFLITO DE INTERESSES

Não se aplica.

LICENÇA DE USO

Este artigo está licenciado sob a Licença Creative Commons CC-BY International. Com essa licença você pode compartilhar, adaptar, criar para qualquer fim, desde que atribua a autoria da obra.

\section{HISTÓRICO}

Recebido em 08/03/2019

Reapresentado em 26/07/2019

Reapresentado em 24/10/2019

Aprovado em 18/12/2019 